OPEN ACCESS

Edited by:

Jing Zhang,

Shanghai Jiao Tong University, China

Reviewed by:

Mau-Sun Chang,

National Taiwan University, Taiwan

Rauf Ahmad Najar,

University of Rochester, United States

*Correspondence:

Juan Chen

chenjuan2014@cqmu.edu.cn

${ }^{\dagger}$ These authors have contributed equally to this work

Specialty section:

This article was submitted to Molecular and Cellular Oncology,

a section of the journal

Frontiers in Oncology

Received: 20 September 2021 Accepted: 15 November 2021 Published: 03 December 2021

Citation:

Yang $M$, Zhou Y, Deng $H$, Zhou $H$,

Cheng S, Zhang D, HeX, Mai L, Chen $Y$ and Chen J (2021) Ribosomal

Protein L23 Drives the Metastasis of

Hepatocellular Carcinoma via

Upregulating MMP9.

Front. Oncol. 11:779748.

doi: 10.3389/fonc.2021.779748

\section{Ribosomal Protein L23 Drives the Metastasis of Hepatocellular Carcinoma via Upregulating MMP9}

\author{
Minli Yang ${ }^{1 \dagger}$, Yujiao Zhou ${ }^{1 \dagger}$, Haijun Deng ${ }^{1 \dagger}$, Hongzhong Zhou $^{2}$, Shengtao Cheng ${ }^{1}$, \\ Dapeng Zhang ${ }^{1}$, Xin He ${ }^{1}$, Li Mai ${ }^{3}$, Yao Chen ${ }^{4}$ and Juan Chen ${ }^{1 *}$ \\ 1 The Key Laboratory of Molecular Biology of Infectious Diseases Designated by the Chinese Ministry of Education, \\ Chongqing Medical University, Chongqing, China, ${ }^{2}$ Department of Clinical Laboratory, Shenzhen Institute of Translational \\ Medicine, The First Affiliated Hospital of Shenzhen University, Shenzhen Second People's Hospital, Shenzhen, China, \\ ${ }^{3}$ Department of Clinical Laboratory, The Second Affiliated Hospital, Chongqing Medical University, Chongqing, China, \\ ${ }^{4}$ Medical Examination Center, The Second Affiliated Hospital, Chongqing Medical University, Chongqing, China
}

Hepatocellular carcinoma $(\mathrm{HCC})$ is one of the leading causes of cancer-related deaths globally. Tumor metastasis is one of the major causes of high mortality of HCC. Identifying underlying key factors contributing to invasion and metastasis is critical to understand the molecular mechanisms of HCC metastasis. Here, we identified RNA binding protein L23 (RPL23) as a tumor metastasis driver in HCC. RPL23 was significantly upregulated in HCC tissues compared to adjacent normal tissues, and closely related to poor clinical outcomes in HCC patients. RPL23 depletion inhibited HCC cell proliferation, migration and invasion, and distant metastasis. Mechanistically, RPL23 directly associated with 3'UTR of MMP9, therefore positively regulated MMP9 expression. In conclusion, we identified that RPL23 might play an important role in HCC metastasis in an MMP9dependent manner and be a potential therapeutic target for HCC tumorigenesis and metastasis.

Keywords: RPL23, HCC, metastasis, RNA stability, MMP9

\section{INTRODUCTION}

Hepatocellular carcinoma (HCC) is the predominant malignancy of the liver and ranks as the third most common cause of cancer-related death worldwide $(1,2)$. Despite the innovative progress of HCC management, most are diagnosed at advanced stage when the therapeutic options are limited. As an aggressive malignancy, HCC metastatic spread is the main obstacle to treatment and extension of long-term survival $(3,4)$. However, the underlying mechanisms of HCC metastasis 
have not yet been fully explored. Therefore, deepening the understanding of molecular mechanisms of HCC metastasis is an urgent need to develop novel therapeutic approaches.

RNA-binding proteins (RBPs) are critical regulators of gene expression by which involved in various aspects of RNA metabolism, such as splicing, modification, stability, and translation (5-8). Growing number of studies have revealed that altered RNA metabolism due to dysfunction of RBP plays an important role in cancer progression, especially cancer cell metastasis $(9,10)$. Human ribosomal protein L23 (RPL23), a novel RBP, has been reported that involved in various physiological and pathological processes, including cell proliferation, cell apoptosis and cycle arrest. For example, in higher-risk myelodysplastic syndrome (MDS) patients, studies showed that overexpression of RPL23 was associated with the abnormal apoptotic resistance in CD34+ cells $(11,12)$. Watanabe et al. demonstrated that GRWD1 expression reversed the RPL23mediated inhibition of anchorage-independent growth in HCT116 cells by negatively regulating RPL23 via the ubiquitin-proteasome system (13). Meng and co-workers confirmed that RPL23MDM2-p53 pathway could coordinate with the p19ARFMDM2-p53 pathway against oncogenic RAS-induced tumorigenesis (14). However, much of those studies on RPL23 focus particularly on its effect in cell apoptosis, the underlying functions and mechanisms of RPL23 in HCC metastasis has been underestimated. Thus, the aim of this study is to examine the effects of RPL23 on the metastasis of HCC and to elucidate the underlying mechanisms.

Importantly, extracellular matrix degradation, mediated mainly by matrix metalloproteinase (MMP) family (15), plays a critical role in cancer cell metastasis. In particular, MMP9, a member of MMP superfamily, has been confirmed to be deeply involved in the metastasis of liver cancer (16-18). Moreover, it has also been reported that RNA binding protein HuR could increase the expression of MMP9 via maintaining MMP9 mRNA stability (19), indicating a potential underlying association between RBPs and MMP9 expression.

In this study, we have evaluated the expression and prognostic value of RPL23 in HCC, then further explored the effect of RPL23 in HCC migration and invasion by interacting with MMP9 both in vitro and in vivo. Further, RPL23 could enhance MMP9 expression by stabilizing MMP9 mRNA, thus to promote HCC metastasis. Taken together, our results demonstrated that RPL23 promotes HCC metastasis by regulating the mRNA stability of MMP9, implying that RPL23 could be a potential therapeutic target for HCC.

\section{MATERIALS AND METHODS}

\section{HCC Tissue Samples}

HCC tissues and paired adjacent non-tumor tissues were obtained from 60 patients who underwent surgical resection for HCC at the First Affiliated Hospital of Chongqing Medical University in Southwest China, with the approval of the Institutional Review Board of Chongqing Medical University. The patients provided informed consent and had not received any prior radiotherapy or chemotherapy. All specimens were frozen immediately after surgery and stored in liquid nitrogen until use.

\section{Cell Culture}

HLE and MHCC97H cell lines were obtained from the Cell Bank of the Chinese Academy of Sciences (Shanghai, China). Huh7 was obtained from the Heath Science Research Resource Bank (HSRRB). Cells were cultured in Dulbecco's Modified Eagle's Medium (DMEM), supplemented with $10 \%$ fetal bovine serum (Gibco-BRL), 100U/ml penicillin, and $100 \mu \mathrm{g} / \mathrm{ml}$ streptomycin at $37^{\circ} \mathrm{C}$ in $5 \% \mathrm{CO} 2$. All the cells were examined negative for mycoplasma.

\section{Antibodies, Plasmids and Chemicals}

The complementary DNA of full-length RPL23 was amplified by polymerase chain reaction and inserted into the pcDNA3.1-Flag vector at EcoRI and XhoI restriction sites. The MMP9 vector was purchased from OriGene Technologies (Rockville, MD). The specific short hairpin RNA of RPL23 (shRPL23\#1: GCAAACCAGCTCAGAAATT, shRPL23\#2: GAGTCATAGT GAACAATAATT) were obtained from GenePharm (Shanghai, China). Actinomycin D was purchased from Sigma (SBR00013). Mitomycin C was purchased from Selleck (S7417).

\section{RT-qPCR Analysis}

Total RNAs were obtained from the cultured cells or tumor tissues using Trizol reagent (Invitrogen, USA). RNA was quantified by absorbance at $260 \mathrm{~nm}$ with a NanoDrop One (Thermoscientific). For RT-qPCR, $1 \mu \mathrm{g}$ of RNA was reverse transcribed into cDNA using the Reverse Transcription Kit (BioRad, USA). qRT-PCR was carried out using SYBR Green (Roche, Germany), and $\beta$-actin was used as control. Primer sequences used for RT-qPCR were listed in Supplementary Table 1.

\section{Western Blot Analysis}

Cells were washed twice with ice-cold phosphatebuffered saline (PBS), collected in RIPA buffer with protease inhibitor cocktails (Roche, Indianapolis, IN) and lysed on ice for $15 \mathrm{~min}$. Lysates were centrifuged for $5 \mathrm{~min}$ at $13000 \times \mathrm{g}$ at $4^{\circ} \mathrm{C}$ and the concentration of protein was measured using a bicinchoninic acid assay (Thermo Fisher Scientific). Protein lysates were fractionated by SDS-PAGE and transferred onto PVDF membranes. The primary antibodies were as follows: rabbit anti-RPL23 (Proteintech, 16086-1-AP), rabbit anti-MMP9 (OriGene, TA326652), anti-GAPDH (Santa Cruz Biotechnology, sc-365062). Selected blots were quantified by using Image J (NIH, USA).

\section{In Vitro Assays for Migration and Invasion}

Cell transwell chambers with or without matrigel (24-well plate, $8 \mathrm{~m}$ pores; $\mathrm{BD}$ Biosciences) were used to assess cell migration and invasion. For migration assay, $1 \times 10^{5} \mathrm{HCC}$ cells with different treatments were seeded into the upper chamber of transwells and cultured in serum-free DMEM at $37^{\circ} \mathrm{C}$ for $18 \mathrm{~h}$, while medium with $10 \%$ FBS was put into the lower chamber. For invasion assay, indicated cells were seeded in the upper chamber with 
matrigel-coated membrane. After a certain time, migrated or invaded cells were fixed in 95\% methanol and stained with $0.1 \%$ crystal violet dye. The number of migrated or invaded cells in five different high-magnification fields $(40 \times)$ were counted under an inverted microscope. To rule out effects of different cell proliferation rates that might alter the results, cells were treated with $10 \mathrm{ug} / \mathrm{mL}$ of mitomycin $\mathrm{C}$ for $2 \mathrm{~h}$ before the assay was performed.

\section{Wound-Healing Assay}

For wound-healing assay, equal numbers of HCC cells were plated into six-well plates. Until confluence, the cell monolayer was scratched with a sterile pipette tip to draw a gap, and washed twice with PBS to remove cell debris. Cells were photographed to record the wound width at $0,24,48 \mathrm{~h}$, respectively. To rule out effects of different cell proliferation rates that might alter the results, cells were treated with $10 \mathrm{ug} / \mathrm{mL}$ of mitomycin $\mathrm{C}$ for $2 \mathrm{~h}$ before the assay was performed.

\section{CCK8 Assay}

For cell proliferation assay, CCK-8 (MedChemExpress, \#HYK0301) assay was used to assess cell viability according to manufacturer's instructions. Different groups of cells at a density of 3000 cells/well were plated in 96-well plate with 100 $\mu \mathrm{l}$ medium and cultured for $0,24,36,48,60,72 \mathrm{~h}$, then maintained in complete DMEM with 10\% CCK8 reagent for 2 $\mathrm{h}$ at $37^{\circ} \mathrm{C}$. The absorbance at $450 \mathrm{~nm}$ was measured by using a plate reader.

\section{Immunohistochemistry (IHC)}

For IHC, HCC tissue samples were fixed in $10 \%$ formalin and embedded in paraffin. The tumor tissue sections were prepared, deparaffinized in xylene, rehydrated with alcohol, and then washed in phosphate-buffered saline (PBS). In order to antigen retrieval, tissue sections were heated at $105^{\circ} \mathrm{C}$ for $20 \mathrm{~min}$ in a citric acid buffer $(0.01 \mathrm{M})$, later dealt with $3 \%$ hydrogen peroxide solution to block the endogenous peroxidase activity and blocked with bovine serum albumin (BSA) for $120 \mathrm{~min}$. Next, antibodies of RPL23 and MMP9 were used to incubate at $4{ }^{\circ} \mathrm{C}$ overnight, then the tissue sections were incubated with horseradish peroxidase (HRP)-conjugated secondary antibody to detect the target protein. Antigen-antibody chromogenic reactions were developed for $12 \mathrm{~min}$. After that, the slides were stained with hematoxylin and dehydration in graded alcohols and xylene. The immunohistochemical staining was analyzed by Image-Pro Plus 6.0 software.

\section{Luciferase Reporter Assay}

The MMP9 promoter fragment was subcloned into the pGL3basic vector to produce pGL3-MMP9-promoter. The vector was cotransfected with shCont or shRPL23. Renilla was cotransfected with reporter plasmid to normalize the transfection efficiency. After transfection for $48 \mathrm{~h}$, the cells were lysed for luciferase activity measurement by using a dual luciferase reporter assay system (Promega, U.S.A.) according to the manufacturer's instructions. The luciferase activity was determined by GloMax microplate luminometer (Promega). All the experiments were repeated at least three times.

\section{Nascent RNA Synthesis Assay}

Cells were incubated with $0.5 \mathrm{mM}$ 5-ethynyl Uridine (5-EU) for $1 \mathrm{~h}$ before harvest. Nascent RNA was captured and subjected to real-time PCR according to protocols of Click-iT ${ }^{\circledR}$ Nascent RNA Capture Kit (MP10365, Thermo, MA, USA).

\section{Cytoskeletal Staining}

The different treatment cells were seeded on the glass coverslips and incubated for $24 \mathrm{~h}$ at $37^{\circ} \mathrm{C}$. Media was removed, cells were gently washed for 3 times with PBS and fixed with $4 \%$ paraformaldehyde for $10 \mathrm{~min}$ at room temperature (RT). Then, cells were permeabilized with $0.5 \%$ Triton X-100 for 15 min. After washing with PBS, cells were counterstained with DyLight $^{\mathrm{TM}} 488$ Phalloidin (CST, \#12935; dilution 1:40) for 10 min to stain F-actin. Subsequently, cell nuclei were stained with 4',6-diamidino-2- phenylindole (DAPI). After air drying for 20 $\mathrm{min}$, the cells were sealed with anti-fluorescent quencher. Finally, images were obtained by confocal laser-scanning microscopy using a Laser Scanning Confocal Microscopy (Leica TCS SP2).

\section{RNA Immunoprecipitation (RIP) Assay}

RIP assay was performed using the Magna RIP RNA IP kit (17700) from Millipore according to manufacturer's protocol. In brief, HCC cells $\left(2 \times 10^{7}\right)$ were lysed with RNA immunoprecipitation lysis buffer (Millipore, USA) and then incubated with $2 \mu \mathrm{g}$ of rabbit polyclonal anti-RPL23 or non-immunized rabbit IgG at $4^{\circ} \mathrm{C}$ overnight. The RNA protein immunocomplexes were pulled down by 30 ul protein A/G magnetic beads. After RNA purification, qRT-PCR was used to determine the levels of target genes.

\section{RNA Pull-Down Assay}

RNA oligonucleotides labeled with biotin at the 5'-end were synthesized by Integrated DNA Technologies. The RNA sequences used in this study were listed as following, sense-M95'UTR-F: AGACACCTCT GCCCTCACC, sense-M9-5'UTR-F: GGTGAGGGCAGAGGTGTCT; sense-M9-3'UTR-F: TAAT ACGACTCACTATAGGG GGCTCCCGTCCTGCTTTGGC; sense-M9-3'UTR-R: TAAAGGTTAGAGAATCCAAG; M9-CDSF: TAATACGACTCACTATAGGGATGAGCCTCTGGCAGCC CCT; M9-CDS-R: CTAGTCCTCAGGGCACTGCA. In all, 50 pmol Biotinylated RNA oligos were conjugated with $50 \mu \mathrm{l}$ of streptavidin beads (50\% slurry; Thermo Fisher) in a total volume of $300 \mu \mathrm{l}$ of RNA-binding buffer $(20 \mathrm{mM}$ Tris, $200 \mathrm{mM} \mathrm{NaCl}, 6 \mathrm{mM}$ EDTA, $5 \mathrm{mM}$ sodium fluoride and $5 \mathrm{mM} \beta$-glycerophosphate, $\mathrm{PH}$ 7.5 ) at $4^{\circ} \mathrm{C}$ on a rotating shaker for 2 hours. After washing three times with RNA-binding buffer, RNA-beads conjugates were incubated with $100 \mu \mathrm{g}$ of nuclear extracts in $500 \mu \mathrm{l}$ RNAbinding buffer on a rotating shaker overnight at $4^{\circ} \mathrm{C}$.

The beads were then washed thoroughly three times with RNA-binding buffer, eluted with $30 \mu \mathrm{l} 1 \times$ SDS loading buffer and subjected to SDS-PAGE and western blot.

\section{Xenograft Model of Lung Metastasis}

For in vivo tumor metastasis assays, male BALB/C nude mice (6-8 weeks old) were obtained from Shanghai SJA Laboratory Animal Co., LTD and allowed for a week adaptation upon arrival and 
animal experiments were conducted in the Laboratory Animal Center of Chongqing Medical University. $2 \times 10^{6}$ MHCC97 cells infected with shRPL23 or empty vector were suspended in $40 \mu \mathrm{L}$ of a 1:1 (v/v) mixture of a serum-free DMEM/Matrigel solution and then orthotopically implanted into the left hepatic lobe of nude mice. After 6 weeks, Mice were anesthetized with 1-3\% isoflurane and killed by $\mathrm{CO} 2$ inhalation before killing and primary tumor volume and lung metastasis were scored. All of the procedures for handling of animals abided by the guidelines of Chongqing Medical University Animal Care Committee (reference number: 2019002).

\section{Statistical Analysis}

The data were presented as mean \pm standard deviation. All statistical analyses were conducted using GraphPad Prism8 (GraphPad) software. Unless otherwise indicated, experiments were analysed with a two-tailed Student's t-test with a confidence interval of $95 \%$ when the number of groups equalled 2 , or with a parametric ANOVA test when the number of groups was $>2$. The nonparametric $\chi 2$ test was used to assess the correlation between RPL23 expression and the clinicopathological parameters. The correlation between two factors were analyzed by Pearson's test. $\mathrm{P}<0.05$ was defined as statistically significant $\left({ }^{*} \mathrm{P}<0.05\right.$; $\left.{ }^{*} \mathrm{P}<0.01 ;{ }^{* *} \mathrm{P}<0.001\right)$.

\section{RESULTS}

\section{Upregulated RPL23 Expression Is Correlated to Poor Clinical Outcomes in HCC}

Based our previous RNA-sequencing data from 10 pairs of primary HCC tissues with extrahepatic metastasis (EHMH) and 10 pairs of metastasis-free HCC tissues (MFH), ribosomal protein L23 (RPL23) is extremely upregulated in HCC tissues, especially in those tissues with extrahepatic metastasis (EHMH). To broadly investigate the potential function of RPL23 in HCC, the expression of RPL23 was first analyzed in 2 published datasets, The Cancer Genome Atlas Cohort (TCGA) and Gene Expression Omnibus (GEO). As expected, RPL23 expression increased obviously in HCC tissues than that in normal tissues (Figures 1A, B, $p<0.05$ ). Moreover, RPL23 overexpression was clearly associated with advanced tumor grade (Figure 1C, $p<0.0001$ ) and late cancer stage (Figure 1D, $p<0.0001$ ). Kaplan-Meier analysis showed that patients with higher levels of RPL23 had shorter disease-free survival (DFS; Figure 1E, $\mathrm{HR}=1.4, p=0.045$ ) and overall survival (OS; Figure 1F, $\mathrm{HR}=1.6$, $p=0.0069$ ), suggesting that upregulation of RPL23 was closely related to poor clinical outcomes in HCC.

To further confirm the clinical significance of RPL23 expression in HCC, real-time PCR was performed to determine the mRNA level of RPL23 in human HCC tissues (T) and their adjacent nontumoral tissues $(\mathrm{N})$ from 60 patients. The mRNA level of RPL23 was increased in human HCC tissues compared with their adjacent nontumoral tissues (Figure 2A), and the significant upregulation of RPL23 was observed in $87 \%$ of HCC tissues (Figure 2B). Consistently, the protein level of RPL23 was also increased in HCC tissue which assessed by Western blot and IHC (Figures 2C, D). Notably, the expression of RPL23 in EHMH was higher than that in MFH (Figure 2D). Moreover, the expression level of RPL23 was positively corelated to tumor vascular invasion $(p=0.0070)$, lung metastasis $(p=0.0469)$ and TNM stage $(p=0.0346)$ in HCC (Table 1, Supplementary Figure 1A). In addition, the mRNA and protein level of RPL23 was dramatically increased in a panel of liver cancer cells compared to primary hepatocytes ( $\mathrm{PHH}$ ) (Figures 2E, F). Taken together, those data indicated that elevated RPL23 may involve in HCC metastasis and tumor progression.

\section{RPL23 Silencing Inhibited HCC Cells Proliferation, Migration and Invasion In Vitro}

To systemically evaluate the functions of RPL23 in HCC, we first examined the effect of RPL23 knockdown on HCC cell growth and invasion. We chose HLE and MHCC97H cells, which express relatively high level of RPL23 compared with other HCC cell lines. The HLE and MHCC97H cells which stably express short hairpin RNA targeting RPL23 were generated and the efficiency was confirmed by Western blot (Figure 3A). Compared with control cells, knockdown of RPL23 could decrease the proliferation rate in HCC cells (Figure 3B). Moreover, cell migration was decreased by RPL23 depletion which witnessed by wound-healing assay (Figure 3C). Furthermore, transwell assay also confirmed that RPL23 depletion abolished the capacity to migrate and invade in HLE and MHCC97H cells (Figure 3D). Those data suggested that RPL23 may participate in HCC metastasis. It has reported that cytoskeleton remodeling mediated by actin filaments plays an important role in cell metastasis (20), therefore, we examined the formation of actin filaments by using phalloidin staining. The data showed that RPL23 silencing led to the loose of actin filaments compared with the control cells (Figure 3E), which benefit to cell migration and invasion. Overall, these data demonstrated that knockdown of RPL23 could inhibit HCC progression by repressing cell proliferation, migration and invasion.

\section{RPL23 Overexpression Promoted HCC Cells Proliferation, Migration and Invasion In Vitro}

To further confirm the biological role of RPL23 in HCC tumorigenesis, Huh7 cells which stably express RPL23 were constructed (Figure 4A) and the effect of RPL23 overexpression on HCC progression were detected by series of experiments. Consistent with the findings in RPL23 depletion cells, cell proliferation rate was increased in RPL23 overexpression cells which determined by CCK- 8 assay (Figure 4B). Next, the woundhealing assay was conducted to determine the effect of RPL23 on cell migration. As expected, overexpression of RPL23 facilitated cell migration obviously (Figure 4C). In addition, RPL23 overexpression cells were subjected to transwell assay and we found that ectopic expression of RPL23 promoted migration and invasion of HCC cells (Figure 4D). Collectively, these data indicated that overexpression of RPL23 could enhance the ability of HCC proliferation, migration and invasion. 
A

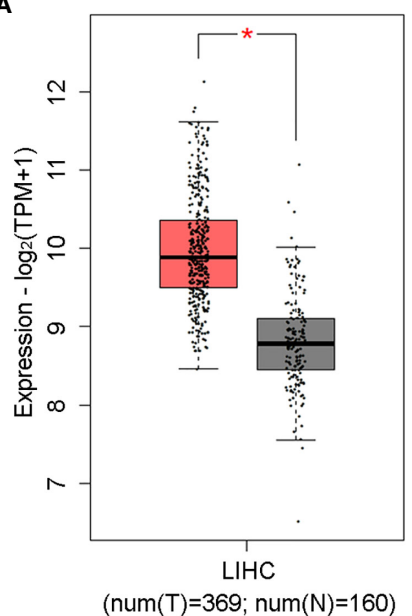

C

Expression of RPL23 in LIHC based on tumor grade

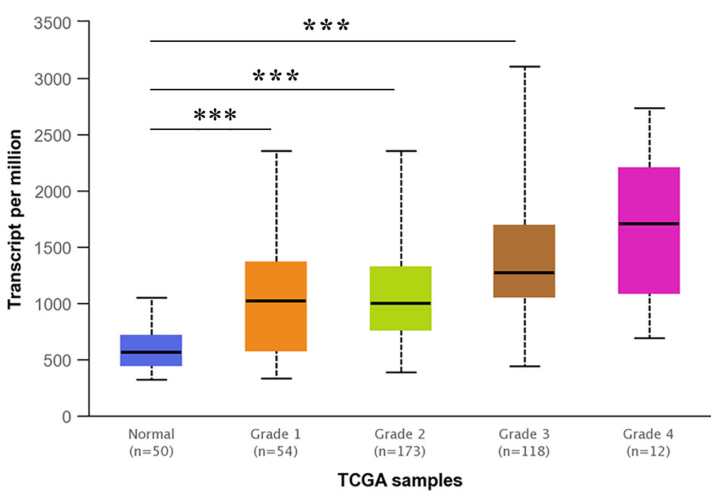

E

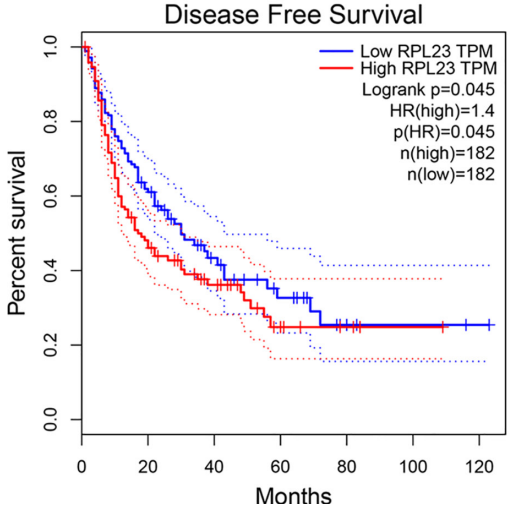

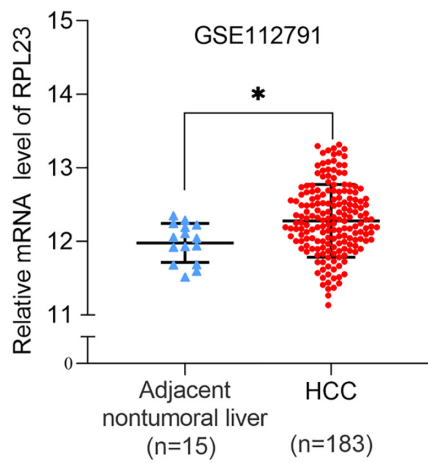

D

Expression of RPL23 in LIHC based on individual cancer stages

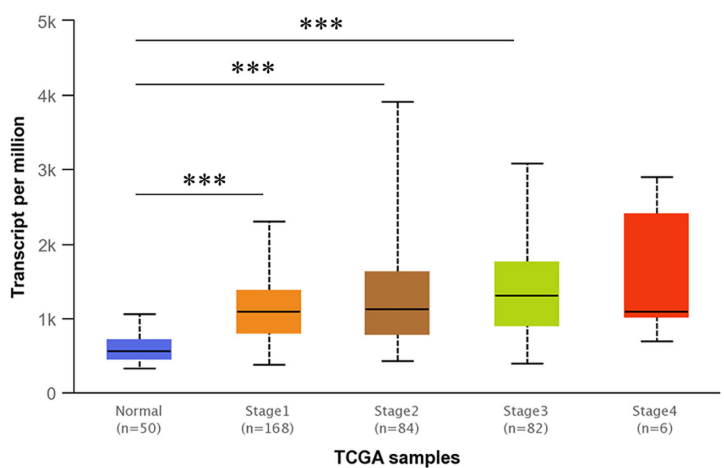

$\mathbf{F}$

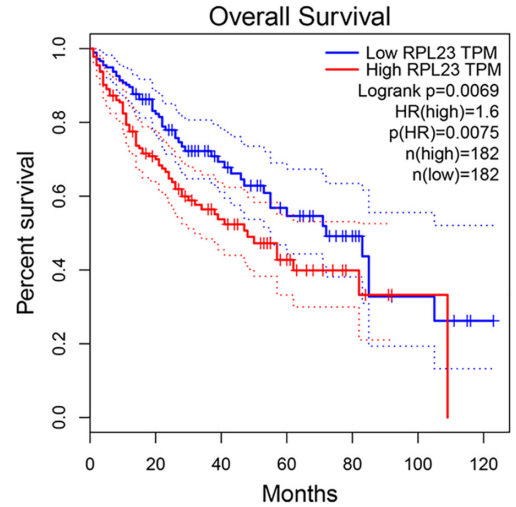

FIGURE 1 | RPL23 overexpression and clinical pathological analysis in HCC tissues according to different public databases. (A) The mRNA level of RPL23 in the adjacent nontumor liver tissues $(n=160)$ and primary liver tumor tissues $(n=369)$ revealed by transcriptome sequencing of TCGA. (B) The mRNA level of RPL23 from RNA-sequencing data on 183 primary human HCC tissues and 15 adjacent nontumor liver tissues of GEO database in the GSE112791 cohort. (C) RPL23 overexpression in HCC based on tumor grade in Ualcan data-mining platform (http://ualcan.path.uab.edu/index.html). (D) RPL23 expression in HCC based on tumor stage. (E) Correlation between RPL23 expression and disease-free survival in TCGA HCC cohort. (F) OS curve of HCC patients based on RPL 23 expression in TCGA HCC cohort. ${ }^{*} \mathrm{p}<0.05$, ${ }^{\star \star \star} \mathrm{P}<0.001$. 
A

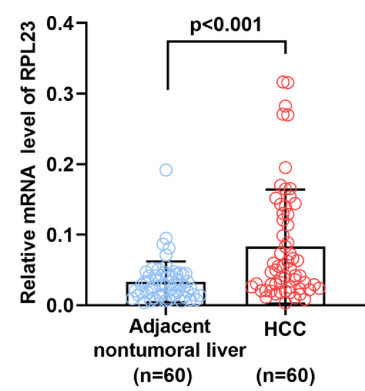

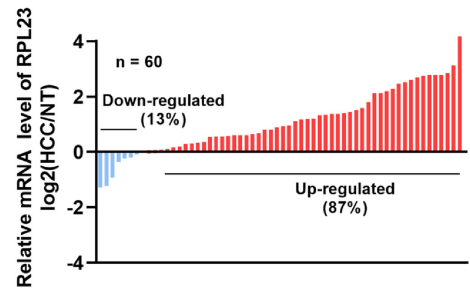

C
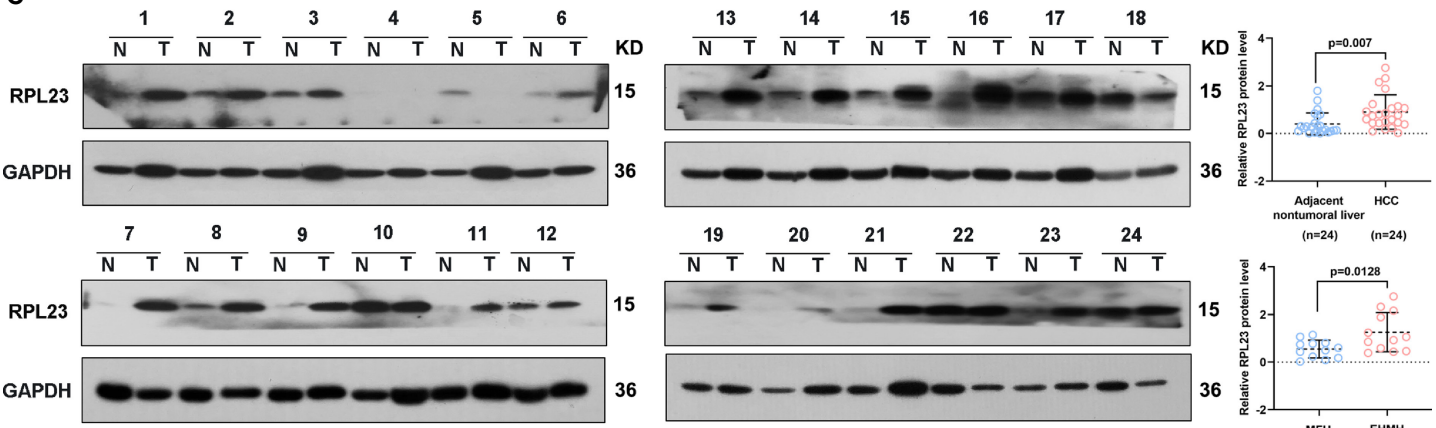
nontumoral liver
$(\mathrm{n}=24)$

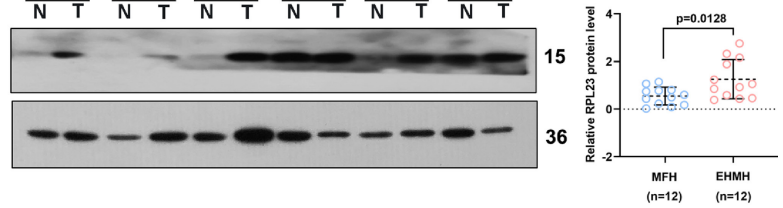

D

HCC patient without metastasis

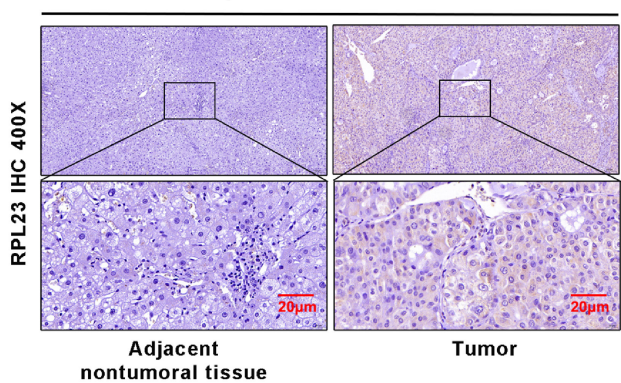

HCC patient with metastasis

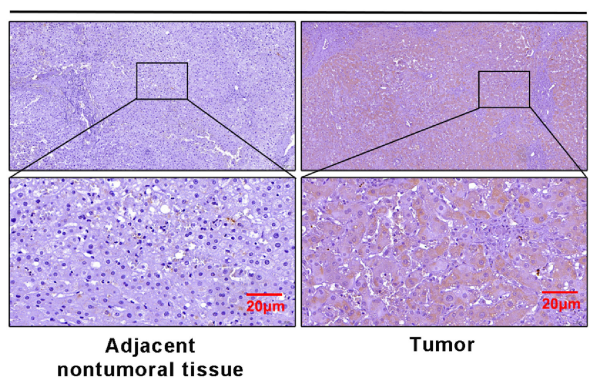

E

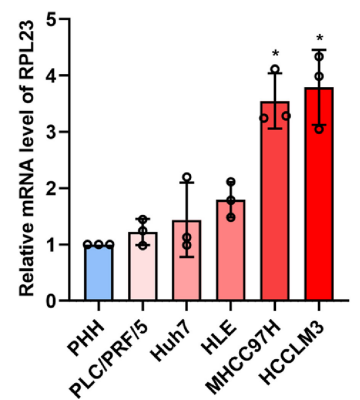

$\mathbf{F}$

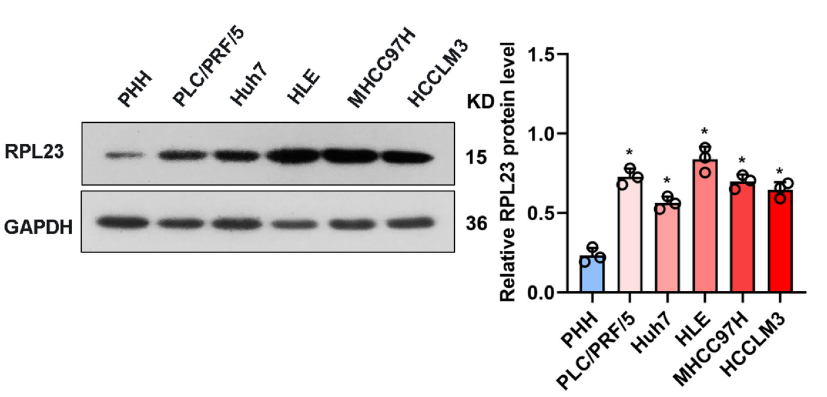

FIGURE 2 | RPL23 levels increased in HCC tissues and overexpressed in different HCC cell lines. (A) The mRNA level of RPL23 in liver cancer was elevated in 60 paired samples of HCC tumor tissues with extrahepatic metastasis (EHMH) and metastasis-free HCC tissues (MFH), as determined by qRT-PCR analyses. (B) RPL23 mRNA levels in 60 HCC and paired non-tumor tissues. (C) RPL23 protein level in 24 paired primary HCC tissues with extrahepatic metastasis (EHMH) and metastasis-free HCC tissues (MFH) was detected by western blotting. GAPDH was used as loading control. (D) Representative immunohistochemical images of RPL23 staining in the paired HCC specimens with or without metastasis. (magnification, 400x) (E, F) GRT-PCR and Western blotting analyses of RPL23 expression in primary human hepatocytes and different HCC cell lines. GAP DH was used as loading control. Representative data are from at least three independent experiments. Data are shown as mean $\pm \mathrm{SD}$. ${ }^{\star} \mathrm{P}<0.05$. 
TABLE 1 | Correlation between RPL23 expression and clinicopathological characteristics in $\mathrm{HCC}$ patients.

\begin{tabular}{|c|c|c|c|c|}
\hline \multirow[t]{2}{*}{ Features } & \multirow[t]{2}{*}{ No. of Specimens } & \multicolumn{2}{|c|}{ expression of RPL23 } & \multirow[t]{2}{*}{$p$ Value } \\
\hline & & High $(n=52)$ & Low $(n=8)$ & \\
\hline \multicolumn{5}{|l|}{ Gender } \\
\hline Males & 45 & 39 & 6 & 0.9999 \\
\hline Females & 15 & 13 & 2 & \\
\hline \multicolumn{5}{|l|}{ Age(years) } \\
\hline$\leq 50$ & 24 & 21 & 3 & 0.9999 \\
\hline$>50$ & 36 & 31 & 5 & \\
\hline \multicolumn{5}{|l|}{$\operatorname{AFP}(\mu \mathrm{g} / \mathrm{L})$} \\
\hline$\leq 20$ & 37 & 33 & 4 & 0.4684 \\
\hline$>20$ & 23 & 19 & 4 & \\
\hline \multicolumn{5}{|c|}{ Liver cirrhosis } \\
\hline Yes & 38 & 34 & 4 & 0.4486 \\
\hline No & 22 & 18 & 4 & \\
\hline \multicolumn{5}{|l|}{ Tumor size } \\
\hline$\leq 3 \mathrm{~cm}$ & 15 & 14 & 1 & 0.6657 \\
\hline$>3 \mathrm{~cm}$ & 45 & 38 & 7 & \\
\hline \multicolumn{5}{|c|}{ Multiple tumor } \\
\hline Yes & 6 & 5 & 1 & 0.9999 \\
\hline No & 54 & 47 & 7 & \\
\hline \multicolumn{5}{|c|}{ Tumor encapsulation } \\
\hline Absent & 40 & 34 & 6 & 0.7068 \\
\hline Present & 20 & 18 & 2 & \\
\hline \multicolumn{5}{|l|}{ PVTT } \\
\hline Yes & 8 & 7 & 1 & 0.9999 \\
\hline No & 52 & 45 & 7 & \\
\hline \multicolumn{5}{|c|}{ Vascular invasion } \\
\hline Yes & 35 & 34 & 1 & $0.0070^{*}$ \\
\hline No & 25 & 18 & 7 & \\
\hline \multicolumn{5}{|c|}{ Lung metastasis } \\
\hline Yes & 19 & 19 & 0 & $0.0469^{*}$ \\
\hline No & 41 & 33 & 8 & \\
\hline \multicolumn{5}{|l|}{ TNM stage } \\
\hline I and I| & 17 & 12 & 5 & $0.0346^{*}$ \\
\hline III and IV & 43 & 40 & 3 & \\
\hline
\end{tabular}

${ }^{*} p<0.05$.

\section{RPL23 Facilitates HCC Metastasis via Enhance MMP9 mRNA Stability}

Epithelial-mesenchymal transition (EMT) is a process whereby epithelial cells acquire mesenchymal features, resulting in decreased adhesion and enhanced migration or invasion. Considering that HCC cell migration and invasion could be enhanced by RPL23, we next analyzed the effect of RPL23 on EMT-associated markers in HCC cells. Based on real-time PCR data, we observed that RPL23 depletion could suppress MMP9 and MMP2 expression, while has no significant effect on other EMT-associated markers, such as N-cadherin, E-cadherin, Vimentin, Smad2 and Twist1 (Figures 5A, B). Due to that MMP9 is the most significant downregulated genes by RPL23 silencing, the protein level of MMP9 were further analyzed by Western blot. The results demonstrated that RPL23 silencing lead to a remarkable decrease of MMP9 protein level (Figure 5C). On the contrary, when RPL23 was overexpressed in Huh7 cells, expression of MMP9 was increased compared to the control cells (Supplementary Figure 2A), suggesting that RPL23 might regulate MMP9 expression at the transcriptional or post-transcriptional level.
To investigate the molecular mechanism underlying RPL23regulated MMP9 expression, we first examined the effect of RPL23 on the promoter region of MMP9 by using a dual-luciferase reporter assay (Supplementary Figure 2B). The results revealed that RPL23 has no significant effect on MMP9 transcription. Next, considering that RPL23 belongs to the RBP family, we examined whether RPL23 could bind to MMP9 mRNA directly. RNA immunoprecipitation (RIP) assay was carried out to assess whether RPL23 directly binds to MMP9 transcripts. The results demonstrated that MMP9 mRNA was significantly enriched in RPL23-IP sample compared with IgG-IP sample (Figure 5D). Indeed, RNA pull-down results showed that RPL23 was directly associated with the 3'UTR of MMP9 mRNA (Figures 5E, F). Given that RPL23 is an RNA-binding protein which can regulate human cancer progress by influencing RNA stability (21), We then performed experiments to elucidate whether the decreased MMP9 mRNA levels were due to a change in RNA synthesis or decay. In nascent RNA capture assays, the rate of MMP9 mRNA synthesis in RPL23 silencing cells were comparable with control cells (Supplementary Figure 2C). Next, we treated RPL23 knockdown cells with actinomycin D to block transcription and measured decay of existing mRNAs by performing time-course real-time PCR. The results revealed that RPL23 depletion could shorten the half-life of MMP9 mRNA in RPL23 knockdown cells $\left(t_{1 / 2}=3\right.$ hours) compared to control cells $\left(t_{1 / 2}=5\right.$ hours) (Figure 5G). Concertedly, RPL23 overexpression could delay the degradation of MMP9 mRNA in HCC cells (Supplementary Figure 2D), suggesting that RPL23 regulates MMP9 mRNA stability without affecting synthesis. Moreover, RPL23 expression positively correlated with MMP9 expression in HCC based on analysis of RPL23 and MMP9 mRNA expression levels in paired tissues from TCGA (Figure 5H). Taken together, our data suggested that RPL23 regulate MMP9 expression via binding to 3'-UTR of MMP9 mRNA.

To further study the functional role of MMP9 in RPL23mediated HCC metastasis, we overexpressed MMP9 in RPL23 silencing cells and the effect on cell growth, migration and invasion were examined. Undoubtedly, the results showed that MMP9 overexpression markedly restored the proliferation ability of RPL23 knockdown cells (Figures 6A, B), and the inhibition of cell migration caused by RPL23 absence was rescued by MMP9 overexpression (Figure 6C). Moreover, transwell assay confirmed that the effect of RPL23 depletion on cell migration and invasion were abolished by MMP9 (Figure 6D). In short, we revealed that RPL23 could facilitate HCC metastasis in an MMP9 dependent manner.

\section{RPL23 Depletion Inhibited HCC Metastasis In Vivo}

To explore the inhibitory effect of RPL23 depletion on HCC metastasis in vivo, MHCC97H cells which stably express short hairpin RNA targeting RPL23 were injected into the left lobe of node mouse to generate the orthotopic nude mouse HCC model. After 6-weeks injection, the mice were sacrificed and subjected to series detection. Consistent with in vitro observation, knockdown of RPL23 significantly decreased both the tumor growth rate and 


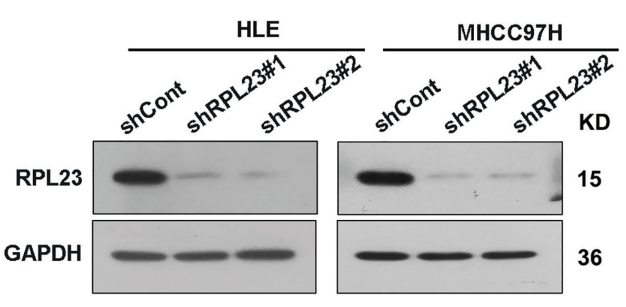

B
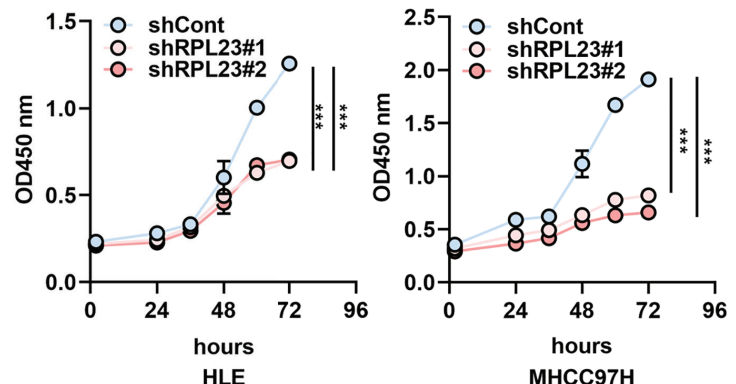

C
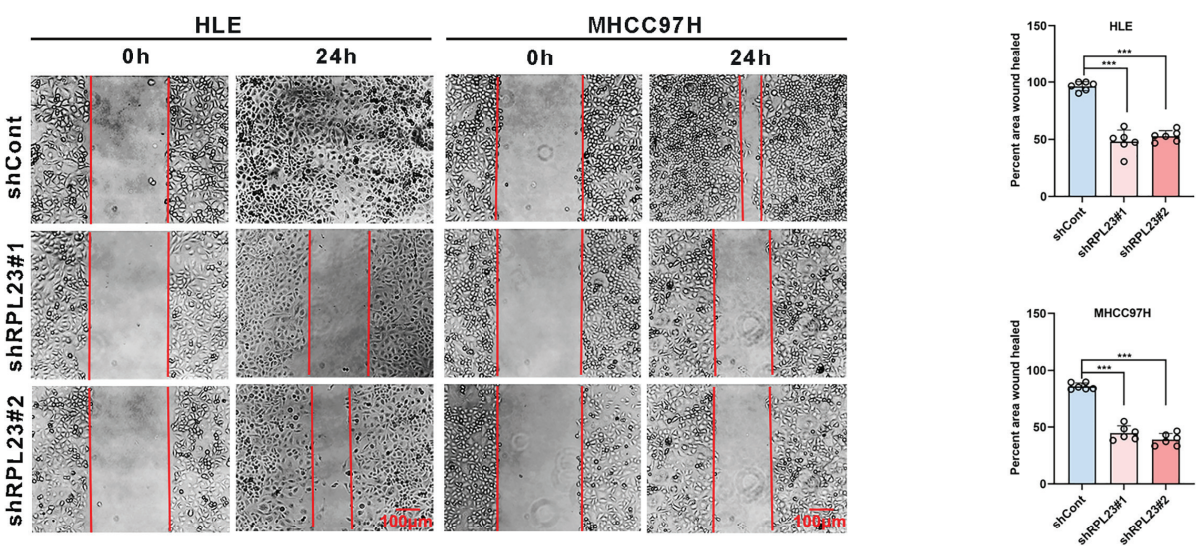
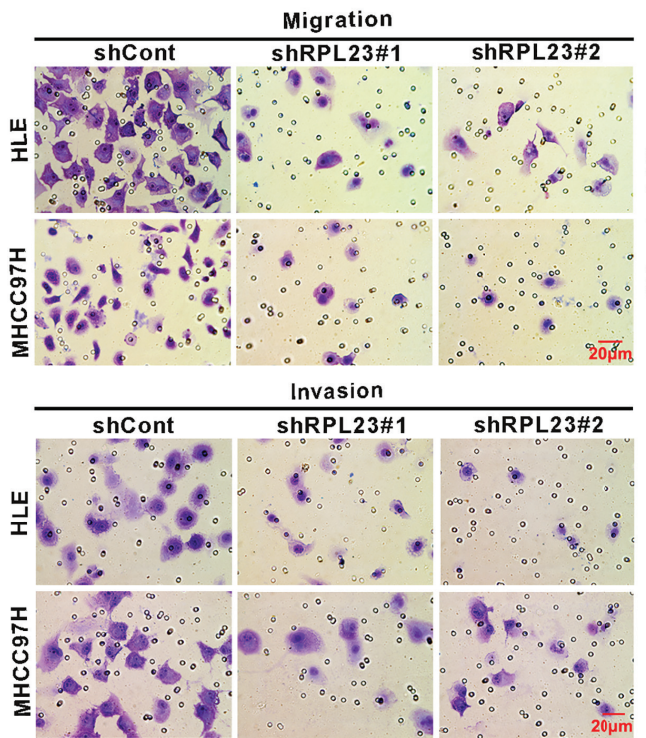

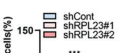

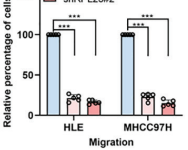

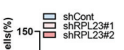

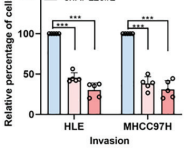

E

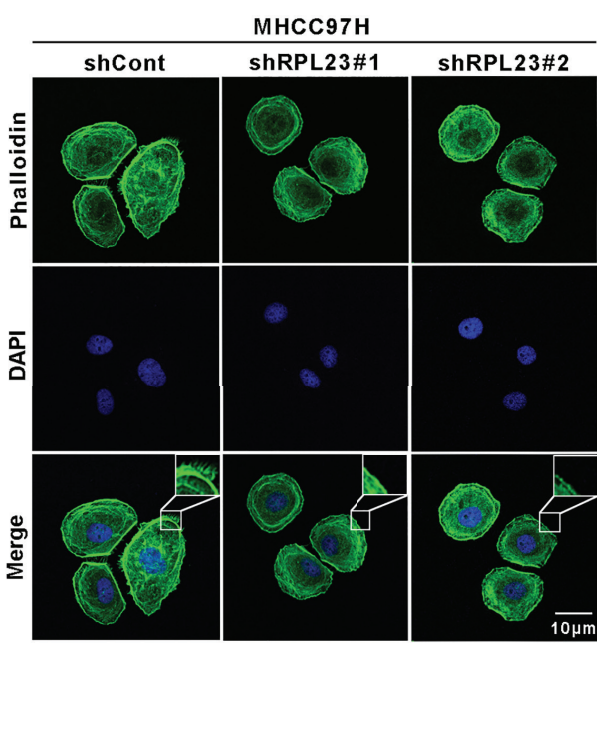

FIGURE 3 | Knockdown of RPL23 significantly suppressed HCC cell proliferation, invasion and migration in vitro. (A) Western blotting was used to access RPL23 expression after transfected with negative control (shCont) or shRNA (shRPL23\#1 and shRPL23\#2) in HLE and MHCC97H cells. GAPDH was used as the internal quantitative control. (B) CCK-8 assay showed that RPL23 knockdown suppressed HCC proliferation capacity. (C) Wound-healing assays were performed to determine the migratory abilities of RPL23-knockdown HCC cells in HLE and MHCC97H cells. The cells were counted from 6 images. (D) Cell migration and invasion as measured by transwell assays were inhibited by knockdown RPL23 in in HLE and MHCC97H cells. The cells were counted from 5 images. (E) Phalloidin (green color) was applied for cytoskeleton staining, while DAPI (blue color) was used to mark the nuclei in RPL23-depleted MHCC97H cells. Magnification, 630x. Representative data are from at least three independent experiments. Data are shown as mean $\pm \mathrm{SD}$. ${ }^{\star \star \star} \mathrm{P}<0.001$. 


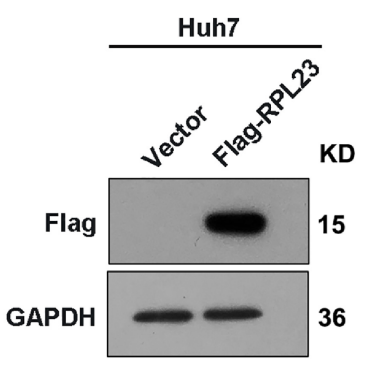

C

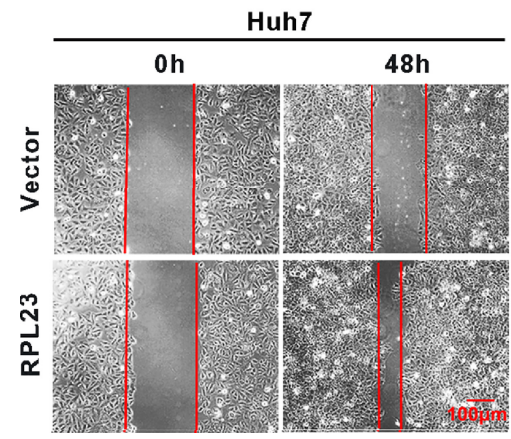

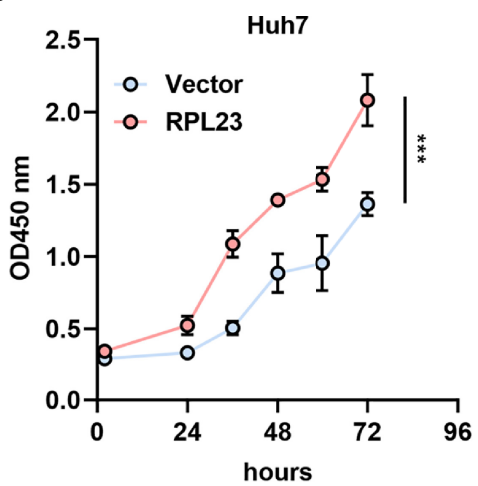

D

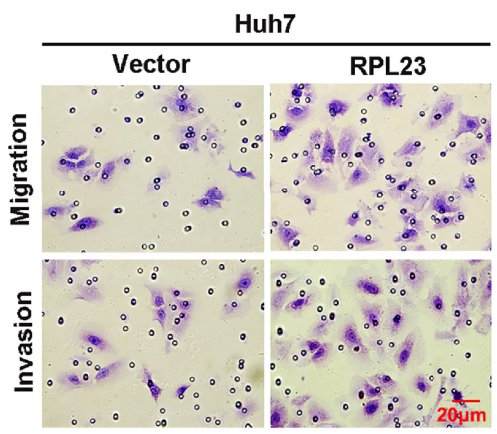

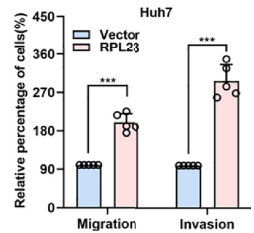

FIGURE 4 | Overexpression of RPL23 promoted HCC cell proliferation, invasion and migration in vitro. (A) The overexpression efficiency of RPL23 was tested by western blotting analysis in Huh7 cells. GAPDH was used as a reference gene. (B) CCK-8 assay was applied to evaluate proliferation ability of Huh7 cells with expression of RPL23. (C) Migratory ability of overexpression RPL23 was detected by wound-healing assay in Huh7 cells. The cells were counted from 6 images. (D) Migratory and invasive ability were assessed by transwell assays in Huh7 cells with RPL23 overexpression. The cells were counted from 5 images. Representative data are from at least three independent experiments. Data are shown as mean $\pm S D$. ${ }^{* \star *} P<0.001$.

tumor size in liver (Figures 7A, B). Moreover, the numbers of lung metastases in RPL23-depletion mice were significantly lower compared with those of control mice (Figure 7C). Mechanistically, immunohistochemistry assay showed that MMP9 expression was apparently decreased in the liver of RPL23 depletion mice (Figure 7D). In summary, those data strongly indicated that RPL23 depletion could down-regulate the expression of MMP9, thus repressing HCC metastasis.

\section{DISCUSSION}

Based on an analysis of 1,225 clinical HCC samples, Dang et al. uncovered that, compared to normal adjacent liver tissues, 526 of RBPs exhibited profound differential expression and a close relationship with the poor prognosis (22). Additionally, several previous studies showed that alterations in the expression and function of RBPs in HCC could amplify the effects of cancer driver genes, accelerate tumor progression, and promote tumor metastasis (8). Up to now, about 1542 human RBPs have been experimentally validated to be involved in diverse physiological and pathological processes including cancers (5). However, the amount of well-characterized RBPs in human cancers including HCC, still remains elusive. In this study, RPL23 was identified as a tumor-promoting oncogene that plays an important role in HCC. RPL23 was significantly upregulated in metastatic HCC tissues and was positively associated with poor survival of HCC patients. RPL23 knockdown suppressed the invasive ability of HCC cells, suggesting RPL23 functions as a pro-tumorigenic factor in HCC progression.

Human ribosomal protein L23 (RPL23), a classical RBP, has been reported to be involved in a variety of human cancers including lung cancer (23), myelodysplastic syndromes (11), gastric cancer (24), and colorectal cancer (25). Additionally, some recent studies revealed that RPL23 might play an important role in cancer metastasis due to its regulatory function on RNA metabolism $(16,26)$. RPL23 was reported that it negatively regulated apoptosis via the RPL23/Miz-1/c-Myc circuit in higher-risk myelodysplastic syndrome (12), functionally inhibit the HDM2 ubiquitin ligase and thereby activate p53, leading to growth inhibition and anti-tumour effects in cases of gastric cancer (27). However, the effect of dysfunction of RPL23 on HCC metastasis still remains unclear. In the current study, besides the role of RPL23 on invasive ability 
A
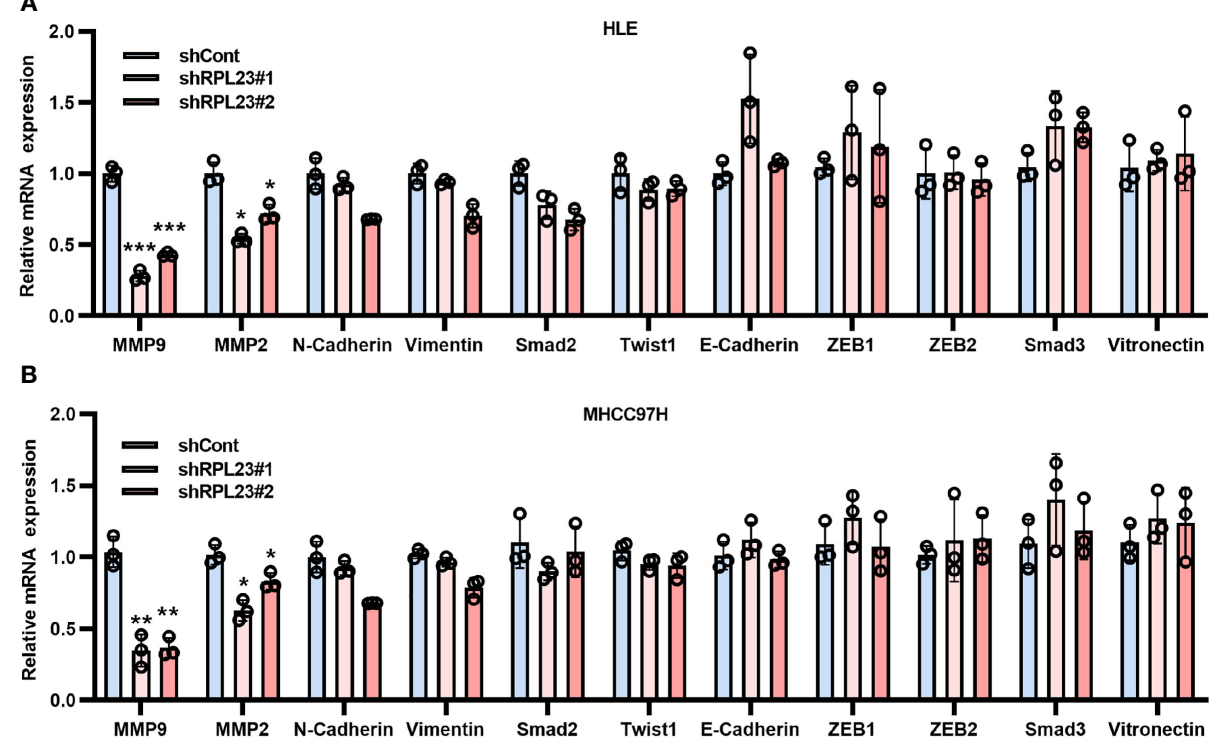

C

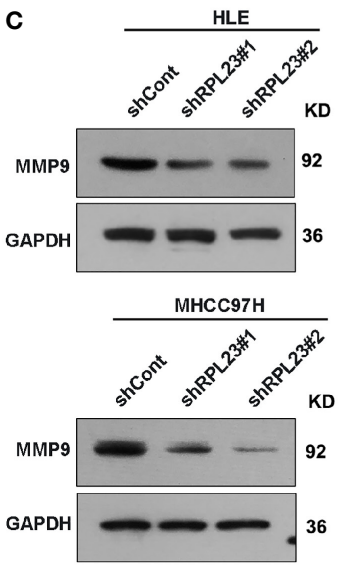

G

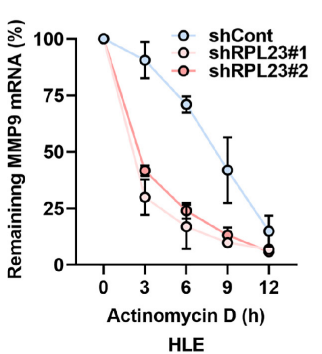

D

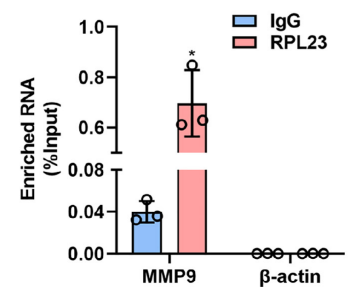

$\mathbf{F}$
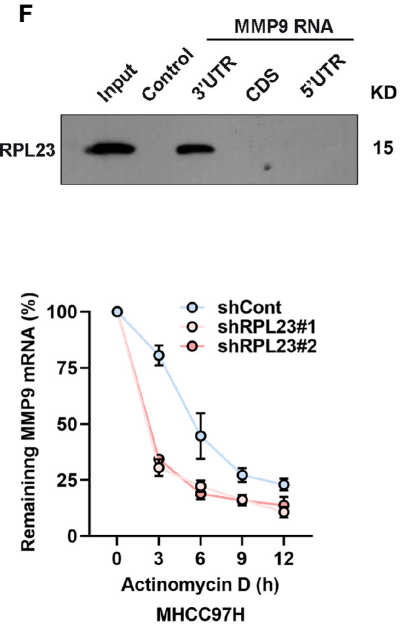

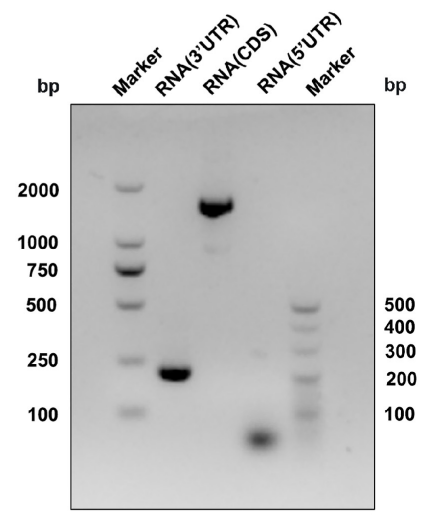

H

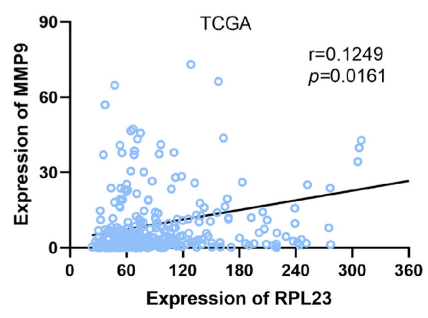

FIGURE 5 | MMP9 is an essential downstream effector of RPL23. (A, B) EMT-related markers (MMP9, MMP2, N-cadherin, Vimentin, Smad2, Twist1 and Ecadherin) were measured on RPL23-depleted HCC cells by qRT-PCR. $\beta$-actin was used as an internal quantitative control. $\left.{ }^{(* \star}{ }^{*}<<0.001\right)$ (C) RPL23 regulated MMP9 protein expression in HLE and MHCC97H cells measured by western blot assay. GAPDH was used as a loading control for western blotting. (D) RIP assays showed that RPL23 directly bound to MMP9 mRNA. (E, F) RNA pull-down results showed that RPL23 was directly associated with the 3'UTR of MMP9 mRNA. (E) shows the biotinylated-MMP9-3'UTR, CDS or 5'UTR transcript in vitro, (F) shows the result of the RNA pull-down assay as analyzed by western blot. Control indicates a control pulldown containing beads only. (G) The half-life of MMP-9 mRNA was reduced after RPL23 knockdown in HLE and MHCC97H cells followed by treatment with $5 \mathrm{ug} / \mathrm{mL}$ actinomycin $\mathrm{D}$ at the indicated times. Error bars represent SEM. $\mathrm{p}$-values (HLE): ${ }^{* *} \mathrm{p}=0.00116$ (shCont vs shRPL23\#1), ${ }^{* *} \mathrm{p}=0.00296$ (shCont vs shRPL23\#2). $p$-values (MHCC97H): ${ }^{* *} p=0.00314$ (shCont vs shRPL23\#1), ${ }^{* *} p=0.00477$ (shCont vs shRPL23\#2). (H) Scatter plot between RPL23 and MMP9 mRNA level in HCC ( $n=371$, from TCGA database). Spearman's correlation coefficients were calculated. Representative data are from at least three independent experiments. ${ }^{\star} \mathrm{p}<0.05,{ }^{\star \star} \mathrm{P}<0.01,{ }^{\star \star \star} \mathrm{P}<0.001$ 


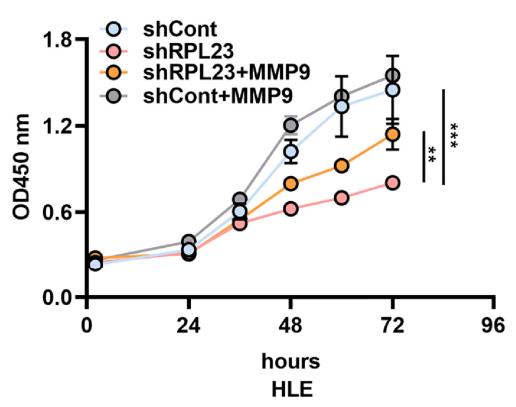

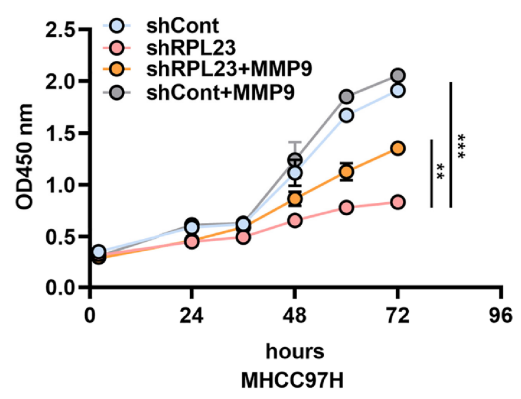

C
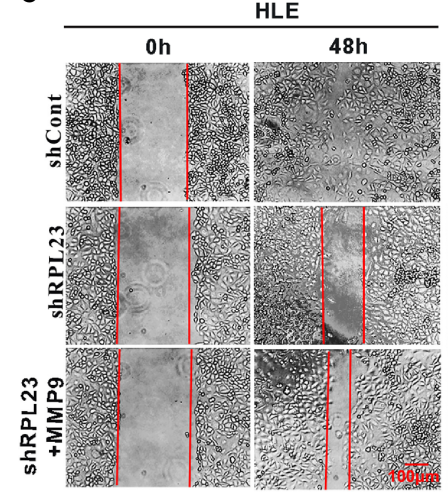

D

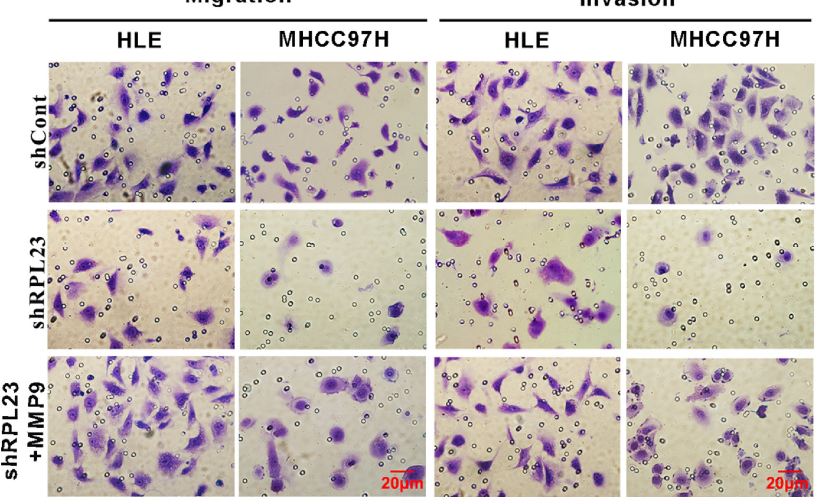

MHCC97H

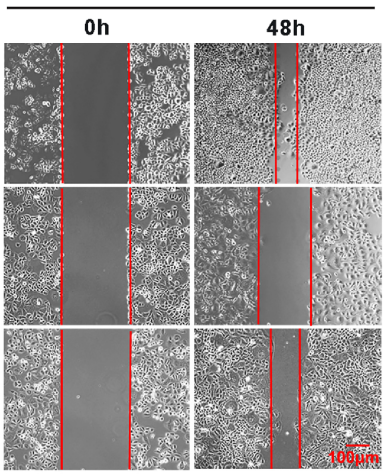

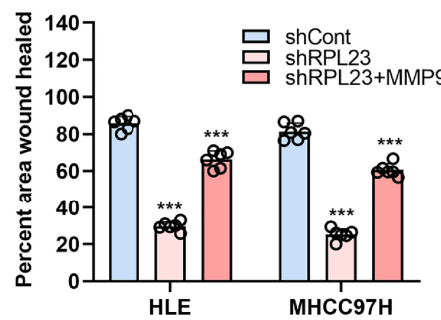

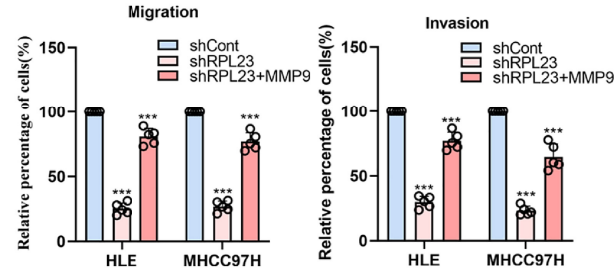

FIGURE 6 | MMP9 overexpression rescues the RPL23 knockdown-induced malignant phenotypes. (A, B) Overexpression of MMP9 rescued the inhibition effect of decreased RPL23 on HCC cell proliferation. (C) overexpression of MMP-9 rescued the repression effect of knockdown RPL23 on HCC cell migration ability by wound-healing assay. The cells were counted from 6 images. (D) Upregulation of MMP-9 could significantly rescued the effects of decreased RPL23 in HLE and $\mathrm{MHCC} 97 \mathrm{H}$ cells for both migration and invasion by transwell assays. The cells were counted from 5 images. Representative data are from at least three independent experiments. Data are shown as mean \pm SD. ${ }^{\star \star} P<0.01,{ }^{\star \star \star} P<0.001$.

in HCC cells, we found that knockdown of RPL23 resulted in the decrease of F-actin filaments, a cytoskeleton constituent that plays critical role in cancer metastasis. Meanwhile, lamellopodia could also reveal the dynamic surface extension of the cell. Furthermore, we uncovered that RPL23 silencing inhibited the distant metastasis of HCC cells in vivo. Taken together, our data suggested that RPL23 might play a pivotal role in HCC metastasis.

Many alterations in tumor cells are identified as contributing factors to the tumor metastasis. Among which, EMT is considered a key step driving cancer metastasis $(28,29)$. Our findings uncovered no significant alteration of expression of some classical EMT-related markers accompanying RPL23 depletion. However, we found MMP9, a critical MMPs protein which degrades nearly all components of ECM (30), was remarkably down-regulated after RPL23 depletion, indicating that MMP9 might be a downstream target of RPL23-mediated metastasis in HCC. Considering the classical function of binding RNA, we therefore speculated whether RPL23 regulates MMP9 via RNA-binding mechanisms. First, we demonstrated that RPL23 could bind to the 3'UTR of MMP9 and enhance the mRNA stability of MMP9, suggesting 
A
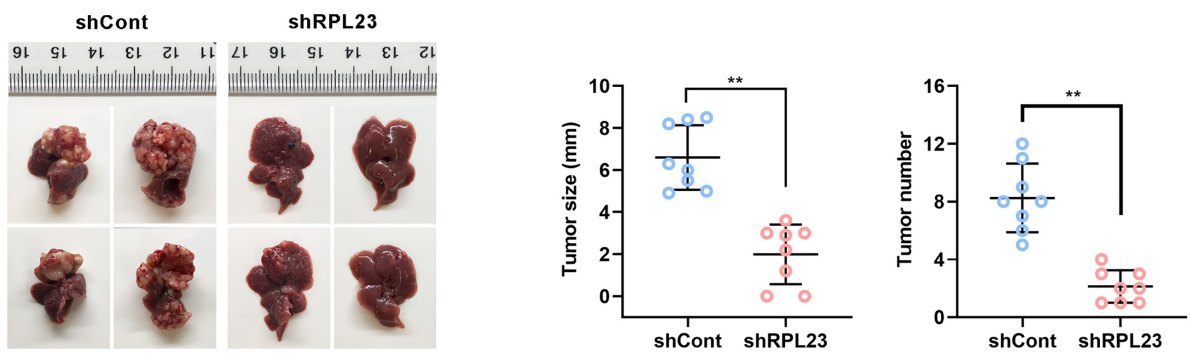

B

C
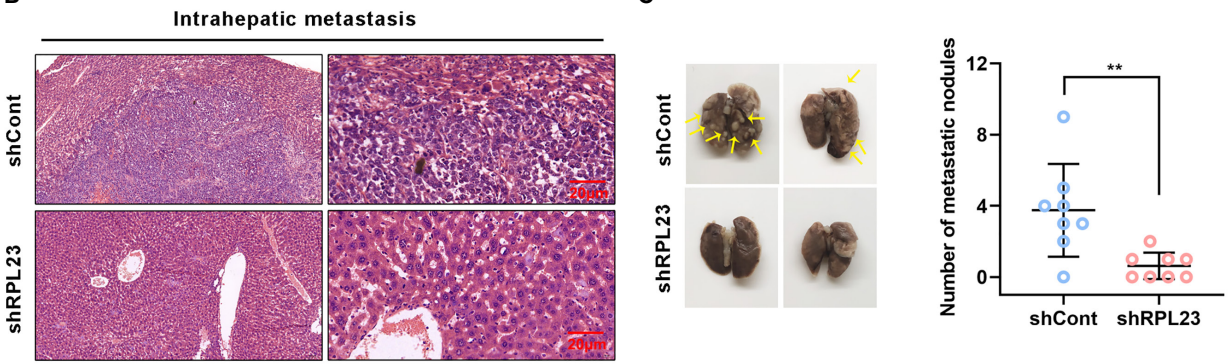

D
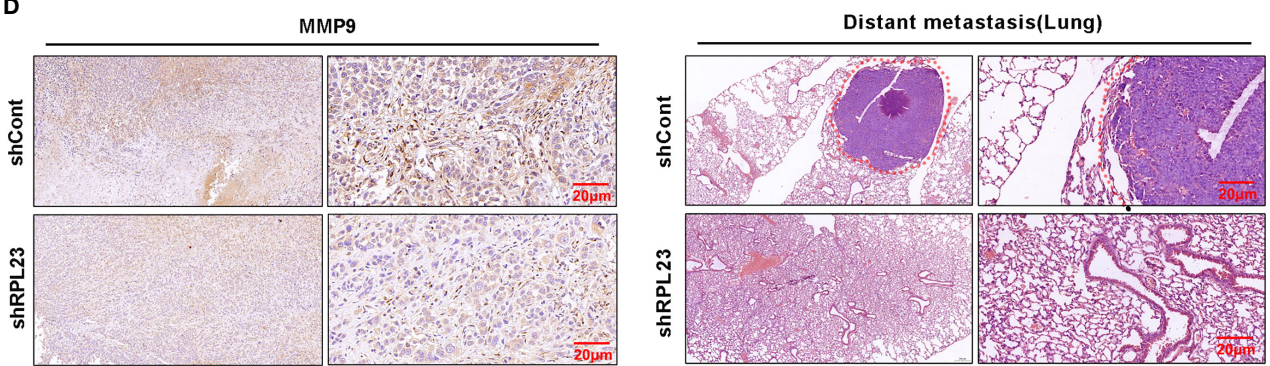

FIGURE 7 | RPL23 knockdown suppressed HCC cell lung metastasis in vivo. The nude mice were orthotopically injected with MHCC97H cells stably depleted RPL23. (A) Representative images (left), volume and number (right) of xenograft liver tumor in nude mice. (B) The presence or absence of metastatic nodules in the liver was evaluated by Hematoxylin-Eosin staining. (C) Representative images of lung metastasis nodules in different groups (up), and evaluated by HematoxylinEosin staining(down). (D) $\mathrm{IHC}$ assay showed MMP9 expression in metastatic xenograft model tissue in different groups. For (A, C), the data were presented as mean $\pm \mathrm{SD}, \mathrm{n}=8$ in each group. ${ }^{\star \star} \mathrm{P}<0.01$.

RPL23 regulated its target mRNA at the post-transcriptional level. Then, we found that overexpression of MMP9 markedly restored the migration and invasion abilities of RPL23 knockdown cells. We further found a significant positive correlation between RPL23 and MMP9 in HCC tissues. Here, our findings revealed a novel mechanism that RPL23 could induced HCC metastasis by stabilizing MMP9 mRNA and increasing its expression, implying a potential therapeutic approach to inhibit HCC metastasis by targeting the RPL23/MMP9 pathway. However, our findings about the interaction between RPL23 and MMP9 are still preliminary and deeper investigations need to be explored in the future.

In summary, we have identified RPL23 as a novel biomarker and prognostic factor for HCC for the first time. RPL23 associates with the 3'UTR of MMP9 mRNA and positively regulates its stability, thus leading to a pro-metastasis effect in HCC. Our finding provides a potential HCC treatment strategy that targets RPL23/MMP9 axis.

\section{DATA AVAILABILITY STATEMENT}

The original contributions presented in the study are included in the article/Supplementary Material. Further inquiries can be directed to the corresponding author.

\section{ETHICS STATEMENT}

The animal study was reviewed and approved by Chongqing Medical University Animal Care Committee. Written informed consent was obtained from the individual(s) for the publication of any potentially identifiable images or data included in this article.

\section{AUTHOR CONTRIBUTIONS}

MY, YZ, HD, and JC designed the study. MY, YZ, HD, HZ, SC, DZ, and $\mathrm{XH}$ performed the experiments and analyses. LM and $\mathrm{YC}$ 
provided the materials. MY, YZ, and SC wrote the manuscript. JC critically reviewed the manuscript. JC supervised the study. All authors contributed to the article and approved the submitted version.

\section{FUNDING}

This work was supported by National Natural Science Foundation of China (81861168035, 81922011 and 81871656 to JC; 31571210 to YC; 81802437 to LM), Postdoctoral Science

\section{REFERENCES}

1. Bertuccio P, Turati F, Carioli G, Rodriguez T, La Vecchia C, Malvezzi M, et al. Global Trends and Predictions in Hepatocellular Carcinoma Mortality. J Hepatol (2017) 67(2):302-9. doi: 10.1016/j.jhep.2017.03.011

2. Huang Z, Zhou J-K, Peng Y, He W, Huang C. The Role of Long Noncoding RNAs in Hepatocellular Carcinoma. Mol Cancer (2020) 19(1):77. doi: 10.1186/s12943-020-01188-4

3. Roayaie S. TACE vs. Surgical Resection for BCLC Stage B HCC. J Hepatol (2014) 61(1):3-4. doi: 10.1016/j.jhep.2014.04.005

4. Dong P, Wang X, Liu L, Tang W, Ma L, Zeng W, et al. Dampened VEPH1 Activates Mtorc1 Signaling by Weakening the TSC1/TSC2 Association in Hepatocellular Carcinoma. J Hepatol (2020) 73(6):1446-59. doi: 10.1016/ j.jhep.2020.06.027

5. Pereira B, Billaud M, Almeida R. RNA-Binding Proteins in Cancer: Old Players and New Actors. Trends Cancer (2017) 3(7):506-28. doi: 10.1016/ j.trecan.2017.05.003

6. Dreyfuss G, Kim VN, Kataoka N. Messenger-RNA-Binding Proteins and the Messages They Carry. Nat Rev Mol Cell Biol (2002) 3(3):195-205.

7. Mitchell SF, Parker R. Principles and Properties of Eukaryotic mRNPs. Mol Cell (2014) 54(4):547-58. doi: 10.1016/j.molcel.2014.04.033

8. Zhang B, Babu KR, Lim CY, Kwok ZH, Li J, Zhou S, et al. A Comprehensive Expression Landscape of RNA-Binding Proteins (RBPs) Across 16 Human Cancer Types. RNA Biol (2020) 17(2):211-26. doi: 10.1080/ 15476286.2019.1673657

9. Dong R, Chen P, Polireddy K, Wu X, Wang T, Ramesh R, et al. An RNABinding Protein, Hu-Antigen $\mathrm{R}$, in Pancreatic Cancer Epithelial to Mesenchymal Transition, Metastasis, and Cancer Stem Cells. Mol Cancer Ther (2020) 19(11):2267-77. doi: 10.1158/1535-7163.MCT-19-0822

10. Liu J, Li H, Mao A, Lu J, Liu W, Qie J, et al. DCAF13 Promotes TripleNegative Breast Cancer Metastasis by Mediating DTX3 mRNA Degradation. Cell Cycle (Georgetown Tex) (2020) 19(24):3622-31. doi: 10.1080/ 15384101.2020 .1859196

11. Wu L, Li X, Xu F, Chang C, He Q, Zhang Z, et al. Over-Expression of RPL23 in Myelodysplastic Syndromes Is Associated With Apoptosis Resistance of CD34+ Cells and Predicts Poor Prognosis and Distinct Response to CHG Chemotherapy or Decitabine. Ann Hematol (2012) 91(10):1547-54. doi: $10.1007 / \mathrm{s} 00277-012-1486-2$

12. Qi Y, Li X, Chang C, Xu F, He Q, Zhao Y, et al. Ribosomal Protein L23 Negatively Regulates Cellular Apoptosis via the RPL23/Miz-1/C-Myc Circuit in Higher-Risk Myelodysplastic Syndrome. Sci Rep (2017) 7(1):2323. doi: 10.1038/s41598-017-02403-x

13. Watanabe S, Fujiyama $H$, Takafuji T, Kayama K, Matsumoto $M$, Nakayama KI, et al. GRWD1 Regulates Ribosomal Protein L23 Levels. Via Ubiquitin-Proteasome System J Cell Sci (2018) 131(15):jcs213009. doi: $10.1242 /$ jcs. 213009

14. Meng X, Tackmann NR, Liu S, Yang J, Dong J, Wu C, et al. RPL23 Links Oncogenic RAS Signaling to P53-Mediated Tumor Suppression. Cancer Res (2016) 76(17):5030-9. doi: 10.1158/0008-5472.CAN-15-3420

15. Castro-Castro A, Marchesin V, Monteiro P, Lodillinsky C, Rossé C, Chavrier P. Cellular and Molecular Mechanisms of MT1-MMP-Dependent Cancer Cell Invasion. Annu Rev Cell Dev Biol (2016) 32:555-76.
Foundation of China (2020M683261 to STC); Creative Research Group of CQ University (CXQT19016 to JC), and Chongqing Natural Science Foundation (cstc2018jcyjAX0114 to JC).

\section{SUPPLEMENTARY MATERIAL}

The Supplementary Material for this article can be found online at: https://www.frontiersin.org/articles/10.3389/fonc.2021.779748/ full\#supplementary-material

16. Li L, Miao H, Chang Y, Yao H, Zhao Y, Wu F, et al. Multidimensional Crosstalk Between RNA-Binding Proteins and Noncoding RNAs in Cancer Biology. Semin Cancer Biol (2021)16:S1044-579X(21)00057-2. doi: 10.1016/ j.semcancer.2021.03.007

17. Yan X-L, Jia Y-L, Chen L, Zeng Q, Zhou J-N, Fu C-J, et al. Hepatocellular Carcinoma-Associated Mesenchymal Stem Cells Promote Hepatocarcinoma Progression: Role of the S100A4-Mir155-SOCS1-MMP9 Axis. Hepatol (Baltimore Md) (2013) 57(6):2274-86. doi: 10.1002/hep.26257

18. Jiang L, Yan Q, Fang S, Liu M, Li Y, Yuan Y-F, et al. Calcium-Binding Protein 39 Promotes Hepatocellular Carcinoma Growth and Metastasis by Activating Extracellular Signal-Regulated Kinase Signaling Pathway. Hepatol (Baltimore Md) (2017) 66(5):1529-45. doi: 10.1002/hep.29312

19. Cui Y-H, Feng Q-Y, Liu Q, Li H-Y, Song X-L, Hu Z-X, et al. Posttranscriptional Regulation of MMP-9 by HuR Contributes to IL-1 $\beta$ Induced Pterygium Fibroblast Migration and Invasion. J Cell Physiol (2020) 235(6):5130-40. doi: 10.1002/jcp.29387

20. Peng J-M, Bera R, Chiou C-Y, Yu M-C, Chen T-C, Chen C-W, et al. Actin Cytoskeleton Remodeling Drives Epithelial-Mesenchymal Transition for Hepatoma Invasion and Metastasis in Mice. Hepatol (Baltimore Md) (2018) 67(6):2226-43. doi: 10.1002/hep.29678

21. Scaturrok M, Sala A, Cutrona G, Raimondi L, Cannino G, Fontana S, et al. Purification by Affinity Chromatography of H1o RNA-Binding Proteins From Rat Brain. Int J Mol Med (2003) 11(4):509-13.

22. Dang H, Takai A, Forgues M, Pomyen Y, Mou H, Xue W, et al. Oncogenic Activation of the RNA Binding Protein NELFE and MYC Signaling in Hepatocellular Carcinoma. Cancer Cell (2017) 32(1):101-14. doi: 10.1016/ j.ccell.2017.06.002

23. Wang J, Zhang Z-Q, Li F-Q, Chen J-N, Gong X, Cao B-B, et al. Triptolide Interrupts rRNA Synthesis and Induces the RPL23-MDM2-p53 Pathway to Repress Lung Cancer Cells. Oncol Rep (2020) 43(6):1863-74. doi: 10.3892/ or.2020.7569

24. Zhang Y-F, Zhang B-C, Zhang A-R, Wu T-T, Liu J, Yu L-F, et al. CoTransduction of Ribosomal Protein L23 Enhances the Therapeutic Efficacy of Adenoviral-Mediated P53 Gene Transfer in Human Gastric Cancer. Oncol Rep (2013) 30(4):1989-95. doi: 10.3892/or.2013.2663

25. Zhang F, Hamanaka RB, Bobrovnikova-Marjon E, Gordan JD, Dai M-S, Lu H, et al. Ribosomal Stress Couples the Unfolded Protein Response to P53Dependent Cell Cycle Arrest. J Biol Chem (2006) 281(40):30036-45.

26. Hodson DJ, Screen M, Turner M. RNA-Binding Proteins in Hematopoiesis and Hematological Malignancy. Blood (2019) 133(22):2365-73. doi: 10.1182/ blood-2018-10-839985

27. Shi Y, Zhai H, Wang X, Han Z, Liu C, Lan M, et al. Ribosomal Proteins S13 and L23 Promote Multidrug Resistance in Gastric Cancer Cells by Suppressing Drug-Induced Apoptosis. Exp Cell Res (2004) 296(2):337-46.

28. Erin N, Grahovac J, Brozovic A, Efferth T. Tumor Microenvironment and Epithelial Mesenchymal Transition as Targets to Overcome Tumor Multidrug Resistance. Drug Resist Update (2020) 53:100715. doi: 10.1016/ j.drup.2020.100715

29. Paolillo M, Schinelli S. Extracellular Matrix Alterations in Metastatic Processes. Int J Mol Sci (2019) 20(19):4947. doi: 10.3390/ijms20194947

30. Yu J, Storer BE, Kushekhar K, Abu Zaid M, Zhang Q, Gafken PR, et al. Biomarker Panel for Chronic Graft-Versus-Host Disease. J Clin Oncol 
Off J Am Soc Clin Oncol (2016) 34(22):2583-90. doi: 10.1200/JCO. 2015.65.9615

Conflict of Interest: The authors declare that the research was conducted in the absence of any commercial or financial relationships that could be construed as a potential conflict of interest.

Publisher's Note: All claims expressed in this article are solely those of the authors and do not necessarily represent those of their affiliated organizations, or those of the publisher, the editors and the reviewers. Any product that may be evaluated in this article, or claim that may be made by its manufacturer, is not guaranteed or endorsed by the publisher.

Copyright $\odot 2021$ Yang, Zhou, Deng, Zhou, Cheng, Zhang, He, Mai, Chen and Chen. This is an open-access article distributed under the terms of the Creative Commons Attribution License (CC BY). The use, distribution or reproduction in other forums is permitted, provided the original author(s) and the copyright owner $(s)$ are credited and that the original publication in this journal is cited, in accordance with accepted academic practice. No use, distribution or reproduction is permitted which does not comply with these terms. 